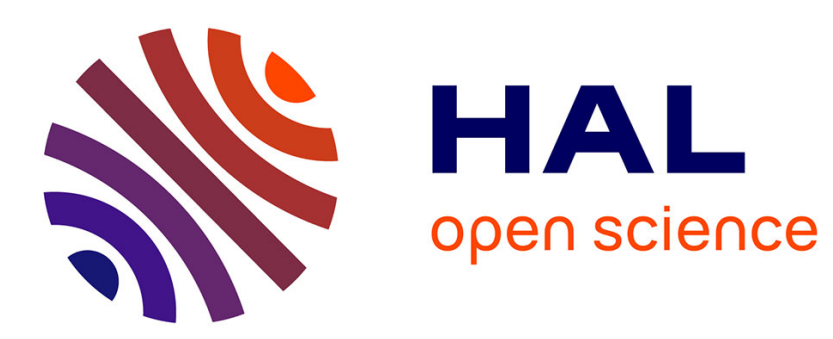

\title{
Controlling refractive index in AlN films by texture and crystallinity manipulation
}

Alaa E Giba, Philippe Pigeat, Stéphanie Bruyère, Thomas Easwarakhanthan, Frank Mücklich, David Horwat

\section{- To cite this version:}

Alaa E Giba, Philippe Pigeat, Stéphanie Bruyère, Thomas Easwarakhanthan, Frank Mücklich, et al.. Controlling refractive index in AlN films by texture and crystallinity manipulation. Thin Solid Films, 2017, 636, pp.537-545. 10.1016/j.tsf.2017.06.057 . hal-03281702

\section{HAL Id: hal-03281702 https://hal.science/hal-03281702}

Submitted on 8 Jul 2021

HAL is a multi-disciplinary open access archive for the deposit and dissemination of scientific research documents, whether they are published or not. The documents may come from teaching and research institutions in France or abroad, or from public or private research centers.
L'archive ouverte pluridisciplinaire HAL, est destinée au dépôt et à la diffusion de documents scientifiques de niveau recherche, publiés ou non, émanant des établissements d'enseignement et de recherche français ou étrangers, des laboratoires publics ou privés. 


\title{
Controlling refractive index in AIN films by texture and crystallinity manipulation
}

\author{
A.E. GIBA ${ }^{1,2}$, P. PIGEAT ${ }^{1}$, S.BRUYERE ${ }^{1}$, T.EASWARAKHANTHAN ${ }^{1}$, F. MUCKLICH ${ }^{2}$, David \\ HORWAT $^{1, *}$
}

${ }^{1}$ Institut Jean Lamour - UMR CNRS 7198-Université de Lorraine, Nancy, France

${ }^{2}$ Department Materials Science and Engineering, Saarland University, D-66123 Saarbrucken, Germany

* corresponding address : david.horwat@univ-lorraine.fr

\begin{abstract}
:
Highly textured polycrystalline aluminum nitride (c-AlN) thin films with hexagonal wurtzite structure have been prepared by direct current reactive magnetron sputtering (DC) of pure aluminum using different compositions of the gas phase and different substrate temperatures. The structure and the microstructure of the films have been investigated by x-ray diffraction (XRD) and transmission electron microscopy (TEM). In addition, the complex refractive index dispersion $\overline{\mathrm{N}}(\lambda)=\mathrm{n}(\lambda)+\mathrm{jk}(\lambda)$ of the films and their thickness have been determined from the normal-incidence transmittance spectra measured in the UV and visible regions. An increase in the XRD intensity of (002) planes associated with the nitrogen contents in the gas composition has been observed. It was found that higher nitrogen content in the gas phase mixture and higher substrate temperature help to improve the preferred orientation of the coatings along the c-axis of the wurtzite cell. This is accompanied by an increase of the ordinary refractive index $\left(\mathrm{n}_{0}\right)$ from 1.8 to 2.1 . This can be attributed to the reduction of the lateral defect density between the columns' interfaces in highly textured samples, which is in line with the TEM observation that shows well aligned columns in the sample with highest ordinary refractive index.
\end{abstract}

Keywords: AlN, Optical properties, Thin films, crystal orientation

\section{1- Introduction}

Aluminium nitride (AlN) is a III-V semiconductor with hexagonal wurtzite structure and exhibits wide optical bandgap of about $6 \mathrm{eV}$. AlN is a promising material due to its specific physical/chemical properties such as high thermal conductivity,[1-2] Excellent piezoelectric coefficient $\mathrm{d} 33$, [3-5] thermal[6] and chemical stabilities[7]. Thanks to these properties, it is attracting great attention for applications in spintronic,[8] surface acoustic wave[9] and 
optoelectronic devices[10]. Many growth methods including chemical vapor deposition (CVD)[11] and physical vapor deposition (PVD) [12-14] have been used to obtain AlN thin films. Magnetron sputtering is one of the PVD methods widely used in large scale in industrial applications due to its low cost and simplicity[15]. It is found that sputtering conditions have a strong impact on the functional properties of AlN films [16-18]. For instance, the residual stress of AIN films is influenced by the total pressure such that the films usually undergo stress transition from compressive to tensile mode when the gas pressure is increased [19]. Hardness and elastic modulus of AlN films have been found to be affected by the total pressure as well[20]. Moreover, the surface roughness that has a direct influence on the performance of the surface wave propagation in acoustic wave devices is also affected by the sputtering conditions. Takeuchi et al.[21]demonstrated that increasing the sputtering power leads to rougher film surface. Furthermore, the optical and acoustic performances of AlN films are strongly depending on the crystallographic orientation. Taniyasu et al. found that the UV emission intensity from AlN films is improved by 25 times in a-plane AlN configuration rather than c-plane configuration[10]. In contrast, Zhang et al.[5]showed that caxis is required for high d33 piezoelectric coefficient. Lobl, et al.[22] further reported that highly c-axis oriented AIN also provides strong piezoelectric coupling needed in SAW devices. Thus, producing AIN with high texture degree deposited at reduced temperature is required from a technological point of view. The relative degree of preferred orientation among the crystal planes can be expressed by the texture coefficient [23-24].This method takes into account the standard intensities of the crystallographic planes compared with the measured intensities of the grown samples and used to confirm the preferred orientation of one plane over the others. For deep further analysis of the crystal quality, rocking curve measurement can be used as useful tool to indicate the perfection of the crystallographic orientation along a specific plane [25]. Therefore, understanding the correlation between the sputtering conditions and the preferred orientation of AlN thin film has established itself as an important topic of interest in research [26]. Currently, $c$-axis oriented AlN films are intensively studied for use in opto-acoustic devices as they exhibit optical and acoustic properties similar to those of single-crystal AlN films [27]. The manipulation of optical properties of this optically transparent material represents an important challenge for future applications, especially in optical quantum circuits. Three functional properties are of primary importance for this purpose. First, c-axis out of plane orientation of AlN thin film is essential for exploiting its largest second order nonlinearity for wavelength conversion and electrooptic effect. Second, the high ordinary refractive index (typically 2.1) of AlN deposited on Si 
wafer is a prerequisite for realizing low loss in silicon integrated AlN photonic circuits[28]. This high refractive index allows to strongly confined the light for long distance leading to emergence a non-linear optical effect on chip scale [29]. Third, the wide range of AIN transparency (bandgap close to $6 \mathrm{eV}$ ) can be exploited for wide operation band devices from UV to IR wavelengths. Combining the above features together, make AIN an excellent candidate for integrated nonlinear optics. This work is dedicated to obtaining highly $c$-axis oriented AlN films deposited on Si substrate and manipulation of their optical properties to achieve high values of refractive index using reactive magnetron sputtering. More particularly, the influence of the nitrogen content in the gas phase composition (nitrogen content) and substrate temperature are linked to the degree of c-axis orientation through the concept of thermally-assisted mobility of adatoms. The corresponding evolution of optical constants is investigated.

\section{2- Experimental section}

AlN thin films were deposited using DC balanced reactive magnetron sputtering. A schematic diagram of the DC magnetron sputtering setup used in this experiment is shown in Fig (1). A high vacuum pressure of $10^{-6} \mathrm{~Pa}$ was obtained by using a turbo molecular pump (BOC EDWARDS EXT 255HI) coupled to a mechanical primary pump. The gas composition, defined as

$N 2 \%=\frac{N_{2}}{\left(N_{2}+A r\right)} \times 100$,

was controlled by adjusting the argon and nitrogen gas flow rates in the range $50-100 \%$ nitrogen and keeping the total pressure (4.4 mtorr) constant using an MKS mass flow controller. The final film thickness was adjusted by using in-situ laser interferential reflectometry (LIR). The deposition time was almost constant for all deposition conditions, around $4 \mathrm{~h} 20 \mathrm{~min}$. An aluminum disk with of 2 inch diameter was used as a target. Sapphire (0001) and Silicon (100) substrates were fixed at $5 \mathrm{~cm}$ distance from the Al target, facing the target axis. The substrates have been ultrasonically cleaned in ethanol for 15 min then by using RF plasma with $20 \mathrm{~W}$ power for $10 \mathrm{~min}$ before starting the deposition to activate the surface and remove the native oxide layer on the silicon wafer as controlled by LIR. The deposition time was adjusted for each deposition condition in order to reach a thickness close to $250 \mathrm{~nm}$. The target current was fixed at $0.05 \mathrm{~A}$ for the set of samples performed with unheated substrates (from $50 \%$ to $100 \% \mathrm{~N}_{2}$ ). In the second set of samples with heated 
substrates, the target current was increased to $0.1 \mathrm{~A}$. The target's voltage changed according to the nitrogen content (from 330-410 V). Squared substrates with 1 x $1 \mathrm{~cm}^{2}$ dimensions have been used. The crystal structure and growth orientation of the films were analyzed by X-ray diffraction (XRD, Brucker D8 Advance with $\mathrm{Cu} \mathrm{K}_{\alpha 1}$ radiation $(\lambda=0.15406 \mathrm{~nm})$ in BraggBrentano configuration). The microstructure was investigated by transmission electron microscopy (JEOL ARM 200-Cold FEG). Transmittance of the AlN films deposited on sapphire substrates was measured in the range from $200 \mathrm{~nm}(6.45 \mathrm{eV})$ to $1120 \mathrm{~nm}(1.10 \mathrm{eV})$ employing a Woollam M-2000 ellipsometer set to its transmission-mode at normal incidence. We restrict ourselves here to the experimentally simpler normal-incidence transmission mode where the light beam travelling across the film probes mostly its bulk optical properties. Moreover, a simple three-phase optical model comprising air, isotropic and uniform film, and sapphire substrate was considered with only the ordinary complex refractive index of the film is sensed by the light's electric field. The normal-incidence transmission mode is a simple and relevant configuration to evaluate the bulk optical properties of the films[30-31].The ordinary refractive index (n) and extinction coefficient $(\mathrm{k})$ of the films were determined by fitting the modeled transmittance to its measured data assuming the simple three-phase optical model: air/isotropic and uniform film/sapphire substrate[32-33]. The optical constants (n, k) of sapphire were taken from the library of WoollamWVase software used for fitting.

The texture coefficient $\mathrm{T}$ of (002) diffracted planes was calculated from XRD data using the following equation:[23-24]

$T(002)=\frac{I_{(002)} / I_{0}(002)}{\frac{1}{N} \Sigma\left[{ }^{I}(h k l) / I_{0_{(h k l)}}\right]}$,

Where $I$ is the measured intensity diffracted by different planes, $I 0$ is standard intensity from a randomly oriented polycrystalline sample (obtained from JCPDS card number 00-025-1133) and $\mathrm{N}$ is the number of diffraction peaks corresponding to diffracting hkl planes. The average size of crystallite, or length of coherence, was estimated using the full width at half maximum of the (002) diffraction peak thanks to the Scherrer's formula[34].

The self-established temperature was measured at the surface of homebuilt thermal probe under different values of discharge current. For this purpose, a tantalum metal plate connected to a k-type thermocouple was placed facing the magnetron axis in the position of the substrate as shown in the inset schematic of Fig (7). 


\section{3- Results}

\subsection{Structure and microstructure}

Figure (2) shows the X-ray diffractograms of the AlN thin films deposited on Si (100) and sapphire substrates for various compositions of the gas phase. In both cases, two peaks are visible on the diffractograms except for $N_{2} \%=100$ where only one peak is observed. The first and second peaks correspond to the signal from (002) and (101) planes of the hexagonal wurtzite structure of AIN, respectively. As well as it is observed that (002) diffraction intensity improves gradually with the $\mathrm{N}_{2} \%$. On contrary, the intensity of the (101) peak deteriorates till the (002) becomes the only detected orientation in the film synthesized under pure nitrogen condition. It is also worth to note that, at $50 \%$ the deposited film on sapphire, unlike on silicon, exhibits no diffraction signals which means absence of parallel planes to the substrates. In order to explore the crystallographic orientation of this sample, XRD in asymmetric geometry configuration and TEM image has been performed. The results, see fig (3a, b), showed crystallites mostly with (101) planes perpendicular to their long axis but this long axis is tilted with respect to the direction normal to the substrate surface. This explains the absence of signal in the x-ray diffractogram measured in symmetric condition that probes only planes parallel to the film surface. Consequently, the texture coefficient of (002) is enhanced as a function of $N_{2} \%$ as observed on fig (4). It can be observed that the trend of texture coefficient on both substrates is the same on samples deposited at rich $\mathrm{N}_{2} \% \geq 70 \%$ conditions. This means that the substrates have insignificant role in determining the preferential orientation at these conditions. On other hand, films deposited on silicon show higher texture coefficient than on sapphire for samples deposited under $50 \%$ and $60 \%$ $\mathrm{N}_{2}$,which is coming from the high intensity of (101) plane on sapphire at these gas compositions. This behavior of AIN on sapphire at lower nitrogen content can be explained by the initial growth mechanism of AlN on sapphire as reported previously[35]. The deposition of AlN on c-sapphire at low temperature can promote the growth of other planes than (002) due to a twinning mechanism resulting from reduced internal electrostatic field that favors the growth with (101) planes parallel to the surface. In addition, the size of crystallites was calculated from the full width at half maximum of the (002) diffraction peak by using the Scherrer's formula [36-37]. Fig (4) shows the size of crystallites increases with $\mathrm{N}_{2} \%$ on both substrates and exhibits a similar trend to the (002) texture coefficient calculated by equation (3.2). This can be confirmed by the monotonic increase with the texture coefficient as shown in fig (5). It is worth mentioning that the crystallites with (101) orientation exhibit average 
size from 67 to $87 \mathrm{~nm}$. Although energy dispersive spectroscopy (EDS) could not quantify correctly the nitrogen content, we have performed EDS measurements of the N/Al ratio and did not find sensible variation of this ratio over the entire range of compositions of the gas phase probed in this study. This is not surprising since the large proportion of nitrogen in the gas phase (50 to $100 \%$ ) and low sputtering rate must ensure complete nitridation of the film. Therefore, compositional changes cannot explain the microstructural changes observed.

In a second series of experiments the substrate was heated to $200{ }^{\circ} \mathrm{C}$ for films prepared under $100 \% \mathrm{~N}_{2}$. Fig. (6) reveals that the XRD intensity from the (002) planes of the AlN films prepared under $100 \%$ nitrogen on a Si substrate heated to $200^{\circ} \mathrm{C}$ increases significantly. It intensifies further when the target current is doubled despite less time is left for the diffusion of adatoms. Raising the target current means increasing in the adatoms flux to the substrate i.e., more energy delivered to the film per time unit and, thereby, higher self-established temperature at the film. To investigate the influence of the target current on the substrate temperature, the temperature was recorded at the thermal probe as a function of discharge current, see fig (7). For more precise temperature measurement, the experiment was established such that the loss in the energy flux $(\Phi)$ dissipated by the connected wires is very small compared to the energy flux of the incident species $\Phi_{i}$ and can be neglected, see inset fig 7. Hence, the measured temperature $\left(T_{m}\right)$ represents the mean thermal energy induced by the incident species. A linear increase in the substrate temperature with the target current with a slope of $670 \mathrm{~K} \mathrm{~A}^{-1}$ was found, which indicates that the higher flux of particles plays a strong role in rising the surface temperature of the growing films.

In order to gain more information on the microstructure, TEM measurements have been performed. All the samples were found to exhibit columnar structure with average thickness of about $250 \mathrm{~nm}$. Fig ( 8 a) shows TEM image with the corresponding selected area electron diffraction (SAED) pattern collected at low magnification of a sample prepared using $100 \%$ $\mathrm{N}_{2}$ and 0.05 A without thermal assistance. The film consists of columns slightly tilted with reference to the growth direction and with a V-shape base that extends over approx. half the film thickness. The SAED collected at the center of the film is composed of partial rings, confirming the polycrystalline nature of the film. Moreover, the signal is brighter along the growth direction at the (002) ring indicating the crystallites are mostly oriented with (002) planes parallel to the substrate. Fig ( $8 \mathrm{~b}$ ) shows the high resolution TEM (HRTEM) of this sample. The Fast Fourier Transform patterns (FFT) of selected areas (squares 1 and 2) on one column of this sample demonstrate that it consists of a single crystal. From the magnified 
view of area 3, one can distinguish a slight tilt in the growth direction between two adjacent columns as well as roughness at the lateral edges. This, along with the V-shaped morphology that extends to rather long distances indicate that the competitive growth is not completed for this film although XRD detected only the (002) orientation. This is in line with the work reported by A.C. Galca et al [38] about the progressive alignment of c-axis of AlN with thickness. In our case, the film thickness kept constant as described below in the sample with thermal assistance, fig $(8 \mathrm{c}, \mathrm{d})$ and the length of this progressive alignment depends on the adatoms mobility .Fig $(8 \mathrm{c})$ shows the TEM and SAED of a sample prepared under $100 \% \mathrm{~N}_{2}$ with a discharge current of $0.1 \mathrm{~A}$ and substrate temperature of $200^{\circ} \mathrm{C}$. This sample prepared with thermal assistance exhibits high crystallites order in the low magnification SAED pattern (inset of fig $8 \mathrm{c}$ ) characterized by more localized and brighter diffraction spots. Figure $(8 \mathrm{~d})$ shows the HRTEM of two columns of this sample and indicates, unlike fig $(8 \mathrm{~b})$, the high crystallites order along the same growth direction even in the lateral area between the columns, see inset fig ( $8 \mathrm{~d})$. This can be explained by earlier termination of the competitive growth that appears to occur in the first $50 \mathrm{~nm}$ of the growth. Columns exhibit smooth lateral edges exhibiting (002) planes perpendicular to the growth direction. The high crystalline order along the same growth direction even in the lateral area between the columns, see inset fig ( 8 d). This can be explained by earlier termination of the competitive growth that appears to occur in the first $50 \mathrm{~nm}$ of the growth. Moreover, columns exhibit smooth lateral edges exhibiting (002) planes perpendicular to the growth direction. This agrees well with the higher diffracted intensity measured for this sample by XRD, that probes atomic planes parallel to the film surface in $\theta / 2 \theta$ configuration. These results are consistence with zones Ic and $\mathrm{T}$ in the structure zone model proposed by Mahieu, S., et al.[39]for films grown without and with thermal assistance, respectively.

\subsection{Optical properties}

Fig. (9) shows the UV-VIS transmittance spectra of the AlN films deposited on sapphire substrates. The film transmittance in the $300-800 \mathrm{~nm}$ wavelength range is high at around $80 \%$ and is almost independent of the nitrogen content in the gas phase. It decreases steeply at the onset of the AlN's fundamental band-gap edge absorption[32] for wavelengths below $250 \mathrm{~nm}$. It is worth noting that the damping in the interference fringes is attributed to intrinsic absorption from the film. Therefore, the attempts to describe the refractive index either by Cauchy's or Sellmeier's empirical dispersions result in these oscillations which are referring to AlN defects. The fact that these dispersions models are well suited to highly transparent 
films, [31-33] makes the use of multiple Kramers-Kronig consistent Gaussian oscillators to express the dispersions $\mathrm{n}(\lambda)$ and $\mathrm{k}(\lambda)$ more relevant to these samples. The Woollam-WVase software has been used to fit three oscillator's parameters, i.e. the central wavelength or the energy position, the strength and the broadening. Excellent fits have been obtained with appreciably low mean-squared errors (maximum likelihood estimators) between $0.10-0.13$ as shown in the inset of fig (9). The good quality of these fits maybe further confirmed by the randomly distributed differences between the modeled and measured transmittance close to zero without any systematic trend. Table 1 displays the best-fit oscillator parameters with their error (90\% confidence limits). The center energy of first and the last oscillators were fixed at their extreme possible wavelengths to avoid parameter correlations. The reasonably low error values also attest the validity of the assumed optical model for our AlN films. Moreover, the fitted film thickness is close to that obtained from both in situ reflectometry and TEM.

Table 1:

\begin{tabular}{|c|c|c|c|c|c|}
\hline $\begin{array}{c}\text { Oscillator } \\
\text { Number }\end{array}$ & Amplitude & $\begin{array}{c}\text { Center energy } \\
(\mathrm{eV})\end{array}$ & $\begin{array}{c}\text { Broadening } \\
(\mathrm{eV})\end{array}$ & $\varepsilon_{1}$ offset & $\begin{array}{c}\text { Thickness } \\
(\mathrm{nm})\end{array}$ \\
\hline 1 & $0.85 \pm 0.01$ & 6.5 (fixed) & $0.76 \pm 0.01$ & & \\
\cline { 1 - 4 } 2 & $0.143 \pm 0.006$ & $5.68 \pm 0.02$ & $0.68 \pm 0.03$ & \multirow{2}{*}{$3.27 \pm 0.03$} & $209 \pm 3$ \\
\cline { 1 - 4 } 3 & $0.064 \pm 0.001$ & $4.81 \pm 0.01$ & $0.86 \pm 0.03$ & & \\
\cline { 1 - 4 } & $0.029 \pm 0.002$ & $3.53 \pm 0.03$ & $2.34 \pm 0.19$ & & \\
\cline { 1 - 4 } & $0.047 \pm 0.001$ & 1.5 (fixed) & $3.27 \pm 0.03$ & & \\
\hline
\end{tabular}

Fig. (10 a, b) displays the energy dispersion of the films' optical constants $\mathrm{k}$ and $\mathrm{n}$ determined by fitting as described above. The extinction coefficient k (fig. 10 a) remains lower than 0.02 in the visible and infrared wavelength ranges. It exhibits weak absorption bands originating from structural disorder and localized defects. The structural or thermal disorder create states that exponentially extend inside the bandgap and form absorbing shoulder appearing just below the bandgap, called Urbach's tail [40]. These absorption bands appear well-simulated by the best-fitted Gaussian oscillators. In more details, the bandgap edge absorption is tracked by the first oscillator. The second and the third oscillators contribute noticeably to the shoulder portion below the bandgap edge from 5.5 to $4.5 \mathrm{eV}$ while the weaker fourth and fifth 
oscillators are describing the remaining bands. Indeed, appearance of wave-like small amplitudes in $n(E)$ are reflecting the Kramers-Kronig relation between $n(E)$ and $k(E)$.

The optical bandgap Eg can be deduced from the Tauc equation that describes the optical absorption in semiconductors having direct electronic transition between their valence and conduction bands: $h v \alpha=B\left(h v-E_{g}\right)^{1 / 2}$, where ' $h v$ ' and $\alpha$ are the photon energy and the material absorption coefficient calculated. The bandgap energy found here, $E \mathrm{~g} \approx 5.92 \mathrm{eV}$, is near to the reported values for polycrystalline AlN films[32]. Apparently, the microstructure and the nitrogen content in the gas phase have no effect on the optical band gap, which is an inherent electronic property of the material. In contrast, the film refractive index $n$ varies appreciably with the amount of $\mathrm{N}_{2}$ in the gas phase (fig. $10 \mathrm{~b}$ ).

It increases linearly with the texture coefficient $\mathrm{T}$ as shown in fig. 11 . Hence, controlling the microstructure represents an interesting strategy to adjust the ordinary refractive index of AIN films. The linear dependency may be attributed to less lattice interferences inside the film between crystallites consisting of (002) and (101) planes parallel to the film surface. Moreover, the sample deposited with thermal assistance under $100 \% \mathrm{~N}_{2}$ exhibits a very high refractive index, close to 2.1 compared to $1.81-1.83$ for samples prepared without thermal assistance. This sample shows the highest crystallinity of the series, in line with the previous interpretation.

\section{4- Discussion}

The effect of the composition of the gas phase, in particular the role of nitrogen species, on the preferred orientation of AlN thin film has been intensively studied in many reports [4143]. In some studies, the role of gas composition was linked to the influence of the film deposition rate that reduced at high nitrogen concentration conditions. This phenomenon was explained by the difference in mass of sputtering ions between the $\mathrm{Ar}^{+}$ions (heavier) and $\mathrm{N}^{2+}$ ions (lighter). As a result, the momentum transferred to the target decreases as the nitrogen content in the gas phase is increased. Thus, the sputtering yield and the deposition rate must be reduced. Consequently, the adatoms have more time to rearrange and find the favorable crystallographic site [43]. Other reports, are considering the effect of the energy of the adatoms in their interpretation. Increasing the energy of adatoms either by increasing their mean free path (e.g. working at low pressure) or applying a large substrate bias voltage in radiofrequency sputtering has been investigated [44]. The film-forming adatoms of high 
energy have sufficient fuel to drive themselves to thermodynamically favorable sites [27]. By combining the above interpretations one can reach the conclusion that it is necessary for the adatoms to have sufficient energy and enough time to find and rest at the most favorable thermodynamic and crystallographic site.

In this work, the deposition rate was very low (about $1 \mathrm{~nm} / \mathrm{min}$ ) and almost constant between all conditions. Hence, its influence on the type of growth can be ruled out. However, the effect of the kinetic energy of the adatoms was considered as a possible origin to the change in microstructure. Owing to the difference between the atomic radius of Ar gas (large) and the molecular radius of $\mathrm{N}_{2}$ (small) gas, $\mathrm{Al}$ atoms sputtered at higher $\mathrm{N}_{2} \%$ are suspected to experience fewer collisions events (i.e. lower scattering probability), increasing their mean free path. The longer mean free path allows the sputtered atoms to keep more energy for the film process. In addition, the target voltage increased with N2\% as seen in fig (4). This is referred to the modification in the plasma conditions and/or the change in target surface composition when the nitrogen content in the gas phase was increased[45]. At high $\mathrm{N}_{2}$ partial pressure, the $\mathrm{Al}$ target is covered by a thin layer of $\mathrm{AlN}_{\mathrm{x}}$. Consistently, the work function of AlN $(5.33 \mathrm{eV})$ is higher than that of metallic $\mathrm{Al}(4.08 \mathrm{eV})$ [46]. The secondary electron emission coefficient is expected to decrease upon target nitriding and the target voltage to increase [47]. The films grown by sputtering process commonly are suffering from bombardment by different kinds of high energetic species, such as sputtered, reflected atoms, and highly energetic negative ions [48]. According to Thompson distribution, [49] the most common energy of the sputtered species equals half the surface binding energy of the target layer (SBE/2). By taking into account the surface binding energy (SBE) of AlN (10.8 eV) and $\mathrm{Al}(3.19 \mathrm{eV})$, sputtered species have higher energy for a nitrided target surface $\left(\mathrm{AlN}_{\mathrm{x}}\right)$ than for a metallic one (Al)[50-51]. The contribution of the backscattered species (neutral or negative) bombarding the substrate surface should also be considered. For neutral reflected particles, the kinetic energy mainly depends on the mass ratio between the target material and the projectile ions $\left(\mathrm{Ar}^{+}\right.$and $\mathrm{N}^{2+}$ ). The energy of backscattered $\mathrm{Ar}$ and $\mathrm{N}$ atoms can be calculated from the following equation:[48]

$E_{p}=\left(\frac{A-1}{A+1}\right)^{2} E_{p o}$

where $\mathrm{A}$ is the mass ratio of $\mathrm{Al}$ to the projectile ions, and Ep0 is the initial energy of the projectile. The calculated energy of backscattered $\mathrm{N}$ atoms (0.049 Ep0) is higher than that of Ar ones $(0.039 \mathrm{Ep} 0)$. Thus, at higher $\mathrm{N}_{2} \%$, the probability of backscattering $\mathrm{N}$ atoms 
increases due to the high $\mathrm{N}_{2}$ partial pressure and splitting the $\mathrm{N}^{2+}$ molecules into two $\mathrm{N}$ atoms. This should deliver more energy to the film surface. Furthermore, with poisoned targets, negative ions that bombard the film surface can play a significant role to increase the mobility of the adatoms that already rested on the film surface and result in improved crystallinity of AIN [52-54]. These ions are formed at the target surface and accelerated towards the substrate with a high kinetic energy corresponding to the cathode sheath potential fall, i.e. roughly the discharge voltage. We recently showed that fast oxygen particles can hold sufficient energy to promote epitaxial growth of $\mathrm{ZnO}$ near-room temperature [55]. Based on the above arguments, depositing AlN at high $\mathrm{N}_{2} \%$ brings more energy to the growing film.

The development of c-axis preferred orientation with increasing $\mathrm{N}_{2} \%$ can be explained considering that (002) planes show the highest packing density and the lowest surface energy[12] compared to the other planes[26, 56]. This feature makes the higher energy adatoms and/or the diffused atoms from other planes tend to lower their energy by resting on (002) planes[57]. As mentioned before, at high $\mathrm{N}_{2} \%$ the adatoms gain more energy to diffuse and rearrange. Therefore, grains with (002) planes parallel to the film surface can grow faster than other planes under such conditions. According to the competitive growth mechanism, planes with the highest growth rate tend to envelop the other planes and to become the preferred orientation upon growth [26, 42, 58]. Considering the above arguments, (002) planes parallel to the film surface should be preferred at higher kinetic energy conditions of particles impinging the film, which is consistent with our results. In addition, the size of crystallites increases with $\mathrm{N}_{2} \%$, as shown in fig (4). This supports the previous hypothesis of improved film crystallinity at higher $\mathrm{N}_{2} \%$. Briefly, our results suggest that both the average crystallite size along [001] and the orientation of AIN thin films can be controlled by optimizing the $\mathrm{N}_{2} \%$ in the gas phase while keeping all the other experimental parameters constant. Furthermore, as shown in fig (6), improving the (002) diffraction intensity when more energy is brought to the substrate by heated up to $200 \mathrm{C}$ and raising the discharge current, is a clear evidence that (002) orientation prefers higher energy of the adatoms [44]. Looking deeply into the microstructure, the HRTEM images not only show the influence of thermal assistance on the crystallinity of the prepared sample but also give indication on the associated mechanism. It suggest that cross diffusion between the adjacent columns is enhanced at higher mobility condition as shown in the magnified insets of fig $(8 \mathrm{~b}, \mathrm{~d})$. On the other hand, enhancing the crystallinity by thermal assistance is supposed to improve the optical properties of the samples. This is what is observed, particularly with the refractive 
index that rises up to 2.1, which is very close to the refractive index of epitaxial AlN thin films[59]. We interpret this as a consequence of a decrease in the density of defects owing to the better columnar alignment, more particularly at the interfaces between columns, for films showing a more pronounced c-axis preferred orientation. This produces denser regions in the transverse direction of the films, which increase the ordinary refractive index compared to the randomly or poorly oriented films. To confirm the strong texture of this sample, rocking curve measurement has been performed at the002 diffraction peak, see fig (12). The narrow FWHM of the rocking curve, about $1.6^{0}$, reflects the high alignment of the crystallites along the $\mathrm{c}$ axis consistently with the calculated large texture coefficient reported in fig (11).This study shows the possibility to adjust and optimize the refractive index of AIN films deposited on nonmatched inexpensive commercial substrates by maximizing the degree of c-axis preferred orientation and crystallinity in soft conditions.

\section{5- Conclusion}

Well crystalline AlN thin films with high degree of c-axis orientation were prepared by reactive magnetron sputtering of an aluminum target. Controlling the preferred orientation by only tuning the $\mathrm{N} 2 \%$ in the gas phase has been achieved. It was found that the synthesis of highly c-axis oriented crystalline AIN is favored by depositing the coatings in nitrogen-rich reactive ambiance. The results have been interpreted on the basis of an improved mobility of adatoms assisted by the bombardment of the films by fast particles. Intentional thermal assistance or increase of the discharge current were found to have similar beneficial influence on the crystallinity of the c-axis oriented films deposited under pure nitrogen conditions. This is explained by thermally-assisted increase in adatoms mobility in both conditions as supported by thermal probe measurement under different discharge currents. The optical constants (n, k) and bandgap of the prepared films have been modeled from spectroscopic ellipsometry measurements in transmission mode. This evidenced the possibility to tune the refractive index with the crystal orientation while keeping constant the bandgap. Our findings suggest that the optical properties of the AlN films can be tuned via their crystallographic orientation which, in turn, varied by the amount of nitrogen in the gas phase.

\section{Acknowledgement}


The first author, A.E. Giba, thanks the European commission for Erasmus Mundus scholarship that financially supports this work within the DocMase $\mathrm{PhD}$ program. Authors thank Sylvie Robert, IJL Université de Lorraine, for rocking curve measurement.

\section{References}

[1] G. Pezzotti, I. Kamada, S. Miki, Thermal conductivity of AIN/polystyrene interpenetrating networks, J. Eur. Ceram. Soc., 20 (2000) 1197-1203.

[2] F. Miyashiro, N. Iwase, A. Tsuge, F. Ueno, M. Nakahashi, T. Takahashi, High thermal conductivity aluminum nitride ceramic substrates and packages, IEEE Trans. Compon. Packag. Manuf. Technol., 13 (1990) 313-319.

[3] K. Giannelli, L. Giovannini, E. Verona, G. Socino, Surface acoustic wave channel waveguides by AIN films, Ultrasonics Symposium, 1996. Proceedings, 1996 IEEE, 1996, pp. 289-292 vol.281.

[4] U. Mastromatteo, F.F. Villa, High sensitivity acoustic wave AIN/Si mass detectors arrays for artificial olfactory and biosensing applications: A review, Sens. Actuator B-Chem., 179 (2013) 319327.

[5] M. Zhang, J. Yang, C. Si, G. Han, Y. Zhao, J. Ning, Research on the Piezoelectric Properties of AIN Thin Films for MEMS Applications, Micromachines, 6 (2015) 1236.

[6] J.-p. Meng, X.-p. Liu, Z.-q. Fu, X.-j. Wang, L. Hao, Thermal stability of AIN films prepared by ion beam assisted deposition, Appl. Surf. Sci., 347 (2015) 109-115.

[7] X.D. Wang, U. Mazur, K.W. Hipps, J.T. Dickson, Chemical stability of laminated AIN/AIN:H films, Thin Solid Films, 240 (1994) 45-51.

[8] C.-w. Zhang, First-principles study on electronic structures and magnetic properties of AIN nanosheets and nanoribbons, J. Appl. Phys., 111 (2012) 043702.

[9] H.L. Kao, W.C. Chen, C. Wei-Cheng, L. Hui-Feng, C. Tzu Chieh, L. Chung Yi, Y.T. Lin, J.I. Chyi, C.H. Hsu, Epitaxial AIN Thin Film Surface Acoustic Wave Devices Prepared on GaN/Sapphire Using LowTemperature Helicon Sputtering System, Jpn. J. Appl. Phys., 47 (2008) 124.

[10] Y. Taniyasu, M. Kasu, T. Makimoto, An aluminium nitride light-emitting diode with a wavelength of 210 nanometres, Nature, 441 (2006) 325-328.

[11] M. Mizuho, U. Norihiko, I. Seiji, T. Kazuo, M. Nobuo, Epitaxial Growth of Aluminum Nitride on Sapphire Using Metalorganic Chemical Vapor Deposition, Jpn. J. Appl. Phys., 20 (1981) 17.

[12] M. He, N. Cheng, P. Zhou, H. Okabe, J.B. Halpern, Preparation of nearly oxygen-free AIN thin films by pulsed laser deposition, J. Vac. Sci. Technol., A, 16 (1998) 2372-2375.

[13] R.D. Vispute, J. Narayan, H. Wu, K. Jagannadham, Epitaxial growth of AIN thin films on silicon (111) substrates by pulsed laser deposition, J. Appl. Phys., 77 (1995) 4724-4728.

[14] J.L. Xie, S. Wickramanayaka, Effect of process pressure on PVD AIN thin film, Electronics Packaging Technology Conference (EPTC), 2014 IEEE 16th, 2014, pp. 849-850.

[15] Front-matter, Handbook of Silicon Based MEMS Materials and Technologies, William Andrew Publishing, Boston, 2010, pp. i-iii.

[16] S. Barth, H. Bartzsch, D. Gloess, P. Frach, T. Herzog, S. Walter, H. Heuer, Sputter deposition of stress-controlled piezoelectric AIN and AISCN films for ultrasonic and energy harvesting applications, IEEE Trans. Ultrason. Ferroelect. Freq. Control, 61 (2014) 1329-1334.

[17] X.S. Miao, Y.C. Chan, Z.Y. Lee, Optical Properties and Reactive Sputtering Conditions of AIN and AISiN Thin Films for Magneto- Optical Applications, J. Electron. Mater., 26 (1997) 21-24.

[18] O. Makoto, T. Hiroto, F. Hiroyuki, Effect of sputtering pressure on crystalline quality and residual stress of AIN films deposited at $823 \mathrm{~K}$ on nitrided sapphire substrates by pulsed DC reactive sputtering, Jpn. J. Appl. Phys., 55 (2016).

[19] G.L. Huffman, D.E. Fahnline, R. Messier, L.J. Pilione, Stress dependence of reactively sputtered aluminum nitride thin films on sputtering parameters, J. Vac. Sci. Technol., A, 7 (1989) 2252-2255. 
[20] Q.-p. Wei, X.-w. Zhang, D.-y. Liu, J. Li, K.-c. Zhou, D. Zhang, Z.-m. Yu, Effects of sputtering pressure on nanostructure and nanomechanical properties of AIN films prepared by RF reactive sputtering, Trans. Nonferrous Met. Soc. China, 24 (2014) 2845-2855.

[21] H. Takeuchi, M. Ohtsuka, H. Fukuyama, Effect of sputtering power on surface characteristics and crystal quality of AIN films deposited by pulsed DC reactive sputtering, Phys. Status Solidi B, 252 (2015) 1163-1171.

[22] H.P. Lobl, M. Klee, O. Wunnicke, R. Kiewitt, R. Dekker, E.V. Pelt, Piezo-electric AIN and PZT films for micro-electronic applications, Ultrasonics Symposium, 1999. Proceedings. 1999 IEEE, 1999, pp. 1031-1036 vol.1032.

[23] S. Navaladian, B. Viswanathan, T.K. Varadarajan, R.P. Viswanath, A Rapid Synthesis of Oriented Palladium Nanoparticles by UV Irradiation, Nanoscale Res. Lett., 4 (2009) 181-186.

[24] H.N. Shah, R. Jayaganthan, D. Kaur, Effect of sputtering pressure and temperature on DC magnetron sputtered CrN films, Surf. Eng., 26 (2010) 629-637.

[25] T. Kumada, M. Ohtsuka, H. Fukuyama, Influence of substrate temperature on the crystalline quality of AIN layers deposited by RF reactive magnetron sputtering, AIP Advances, 5 (2015) 017136.

[26] Y. Kajikawa, S. Noda, H. Komiyama, Comprehensive perspective on the mechanism of preferred orientation in reactive-sputter-deposited nitrides, J. Vac. Sci. Technol., A, 21 (2003) 1943-1954.

[27] G.F. Iriarte, J.G. Rodríguez, F. Calle, Synthesis of c-axis oriented AIN thin films on different substrates: A review, Mater. Res. Bull., 45 (2010) 1039-1045.

[28] C. Xiong, W.H.P. Pernice, H.X. Tang, Low-Loss, Silicon Integrated, Aluminum Nitride Photonic Circuits and Their Use for Electro-Optic Signal Processing, Nano Lett., 12 (2012) 3562-3568.

[29] M. Stegmaier, W.H.P. Pernice, Mode control and mode conversion in nonlinear aluminum nitride waveguides, Opt. Express, 21 (2013) 26742-26761.

[30] G. Bader, P.V. Ashrit, V.-V. Truong, Transmission and reflection ellipsometry of thin films and multilayer systems, Appl. Opt., 37 (1998) 1146-1151.

[31] P. Dirk, S. Philippe Frederic, Methods for the determination of the optical constants of thin films from single transmission measurements: a critical review, J. Phys. D: Appl. Phys., 36 (2003) 1850.

[32] H.-Y. Joo, H.J. Kim, S.J. Kim, S.Y. Kim, Spectrophotometric analysis of aluminum nitride thin films, J. Vac. Sci. Technol., A, 17 (1999) 862-870.

[33] H. Fujiwara, Spectroscopic Ellipsometry: Principles and Applications, John Wiley \& Sons, Ltd, 2007.

[34] H.P. Klug, L.E. Alexander, X-Ray Diffraction Procedures: For Polycrystalline and Amorphous Materials, 1974.

[35] T. Liu, J. Zhang, X. Su, J. Huang, J. Wang, K. Xu, Nucleation and growth of (10¹1) semi-polar AIN on (0001) AIN by Hydride Vapor Phase Epitaxy, Sci. Rep., 6 (2016) 26040.

[36] M. Amirhoseiny, Z. Hassan, S.S. Ng, M.A. Ahmad, Characterizations of InN Thin Films Grown on Si (110) Substrate by Reactive Sputtering, J. Nanomater., 2011 (2011) 7.

[37] M. Akiyama, T. Harada, C.-N. Xu, K. Nonaka, T. Watanabe, Preparation of highly oriented AIN thin films on glass substrates by helicon plasma sputtering and design of experiments, Thin Solid Films, 350 (1999) 85-90.

[38] A.C. Galca, G.E. Stan, L.M. Trinca, C.C. Negrila, L.C. Nistor, Structural and optical properties of caxis oriented aluminum nitride thin films prepared at low temperature by reactive radio-frequency magnetron sputtering, Thin Solid Films, 524 (2012) 328-333.

[39] S. Mahieu, P. Ghekiere, D. Depla, R. De Gryse, Biaxial alignment in sputter deposited thin films, Thin Solid Films, 515 (2006) 1229-1249.

[40] A.R. Zanatta, I. Chambouleyron, Absorption edge, band tails, and disorder of amorphous semiconductors, Phys. Rev. B, 53 (1996) 3833-3836.

[41] R.K. Choudhary, P. Mishra, A. Biswas, A.C. Bidaye, Structural and Optical Properties of Aluminum Nitride Thin Films Deposited by Pulsed DC Magnetron Sputtering, ISRN Materials Science, (2013).

[42] D. Deniz, T. Karabacak, J.M.E. Harper, Competitive growth mechanisms of aluminum nitride thin films deposited by off-normal reactive magnetron sputtering, J. Appl. Phys., 103 (2008) 083553. 
[43] H. Jin, J. Zhou, S.R. Dong, B. Feng, J.K. Luo, D.M. Wang, W.I. Milne, C.Y. Yang, Deposition of c-axis orientation aluminum nitride films on flexible polymer substrates by reactive direct-current magnetron sputtering, Thin Solid Films, 520 (2012) 4863-4870.

[44] M. Clement, E. Iborra, J. Sangrador, A. Sanz-Hervás, L. Vergara, M. Aguilar, Influence of sputtering mechanisms on the preferred orientation of aluminum nitride thin films, J. Appl. Phys., 94 (2003) 1495-1500.

[45] D. Depla, A. Colpaert, K. Eufinger, A. Segers, J. Haemers, R. De Gryse, Target voltage behaviour during DC sputtering of silicon in an argon/nitrogen mixture, Vacuum, 66 (2002) 9-17.

[46] Musarrat Hasan, Hokyong Park, J.-M. Lee, a.H. Hwang, Dual-Metal-Gate Work Function by Controlling Metal Gate Thickness and Composition, Electrochem. Solid State Lett., 11 (2008).

[47] Wang Tao, Jiang Ya-Dong, Yu He, Wu Zhi-Ming, Z. He-Nan, Target voltage behaviour of a vanadium-oxide thin film during reactive magnetron sputtering, Chin. Phys. B, 20 (2011).

[48] K. Ellmer, T. Welzel, Reactive magnetron sputtering of transparent conductive oxide thin films: Role of energetic particle (ion) bombardment, J. Mater. Res., 27 (2012) 765-779.

[49] D. Horwat, A. Anders, lon acceleration and cooling in gasless self-sputtering, Appl. Phys. Lett., 97 (2010) 221501.

[50] F. Chernow, J.A. Borders, D.K. Brice, Ion Implantation in Semiconductors 1976, Springer US, Boston, MA, 1977, pp. 21-29.

[51] T. Kubart, T. Nyberg, S. Berg, Modelling of low energy ion sputtering from oxide surfaces, J. Phys. D: Appl. Phys., 43 (2010) 205204.

[52] E. Iborra, M. Clement, J. Sangrador, A. Sanz-Hervas, L. Vergara, M. Aguilar, Effect of particle bombardment on the orientation and the residual stress of sputtered AIN films for SAW devices, IEEE Trans. Ultrason., Ferroelect., Freq. Control, 51 (2004) 352-358.

[53] T. Kikuo, I. Satoshi, S. Yoshihiro, T. Osamu, High-Energy Particles in AIN Film Preparation by Reactive Sputtering Technique, Jpn. J. Appl. Phys., 22 (1983) 418.

[54] J.G.R. G.F. Iriarte, F. Calle, Effect of substrate-target distance and sputtering pressure in the synthesis of AIN thin films, Microsys. Technol., 6 (2011) 2011.

[55] W. Chamorro, D. Horwat, P. Pigeat, P. Miska, S. Migot, F. Soldera, P. Boulet, F. Mücklich, Nearroom temperature single-domain epitaxy of reactively sputtered $\mathrm{ZnO}$ films, J. Phys. D: Appl. Phys., 46 (2013) 235107.

[56] S.-C. Shi, S. Chattopadhyay, C.-F. Chen, K.-H. Chen, L.-C. Chen, Structural evolution of AIN nanostructures: Nanotips and nanorods, Chem. Phys. Lett., 418 (2006) 152-157.

[57] G. Knuyt, C. Quaeyhaegens, J. D'Haen, L.M. Stals, A model for texture evolution in a growing film, Surf. Coat. Technol., 76-77, Part 1 (1995) 311-315.

[58] A.B. Rodriguez-Navarro, Model of texture development in polycrystalline films growing on amorphous substrates with different topographies, Thin Solid Films, 389 (2001) 288-295.

[59] H.Y. Joo, H.J. Kim, S.J. Kim, S.Y. Kim, The optical and structural properties of AIN thin films characterized by spectroscopic ellipsometry, Thin Solid Films, 368 (2000) 67-73. 


\section{Figure captions}

Fig. 1: Schematic of the experimental setup.

Fig. 2: X-ray diffractograms of c-AlN films synthesized using different $\mathrm{N}_{2} \%$ gas ratio on silicon and sapphire substrates.

Fig. 3: a) Asymmetric XRD and, b) TEM micrograph of sample prepared with 50\% $\mathrm{N}_{2}$ on sapphire.

Fig.4: Texture coefficient, average crystallite size along [001] and target voltage as a function of $\mathrm{N}_{2}$ $\%$ deposited on silicon and sapphire substrates.

Fig. 5: Averaged crystallite size along [001] versus texture coefficient of the AlN thin films deposited on silicon and sapphire substrates.

Fig. 6: X-ray diffractograms of c-AlN films synthesized at $100 \% \mathrm{~N}_{2}$ with different target currents and substrate temperatures.

Fig. 7: Thermal probe temperature as a function of the discharge current. The inset shows the schematic of the home made thermal probe. $\Phi_{\mathrm{i}}$ corresponds to the incident energy flux while $\left(\Phi_{1}, \Phi_{3}\right)$ and $\left(\Phi_{2}, \Phi_{4}\right)$ correspond to the energy dissipated by the thermocouple and holding wires, respectively.

Fig. 8: (A) TEM micrograph and corresponding SAED of AIN films synthesized with $\left(100 \% \mathrm{~N}_{2}, 0.05\right.$ A) without thermal assistance. (B) HRTEM image and FFT patterns of selected areas on one column of this sample. (C) TEM micrograph and corresponding SAED of AlN films synthesized with $100 \% \mathrm{~N}_{2}$ and $0.1 \mathrm{~A}$ at $200^{\circ} \mathrm{C}$. (D) HRTEM image of sample prepared with thermal assistance.

Fig. 9: Optical transmittance of AlN synthesized using different $\mathrm{N}_{2} \%$. Inset: The best fit to the measured transmittance of a selected sample.

Fig. 10: a) The extinction coefficient and, b) Calculated refractive index as a function of the photon energy for AlN films deposited under different compositions of the gas phase.

Fig. 11: Refractive index as a function of the texture coefficient.

Fig. 12: Rocking curve of AlN (001) plane at 002 diffraction peak for sample prepared at $100 \% \mathrm{~N}_{2}$ and $0.1 \mathrm{~A}$ at $200^{\circ} \mathrm{C}$. 
Figure (1)

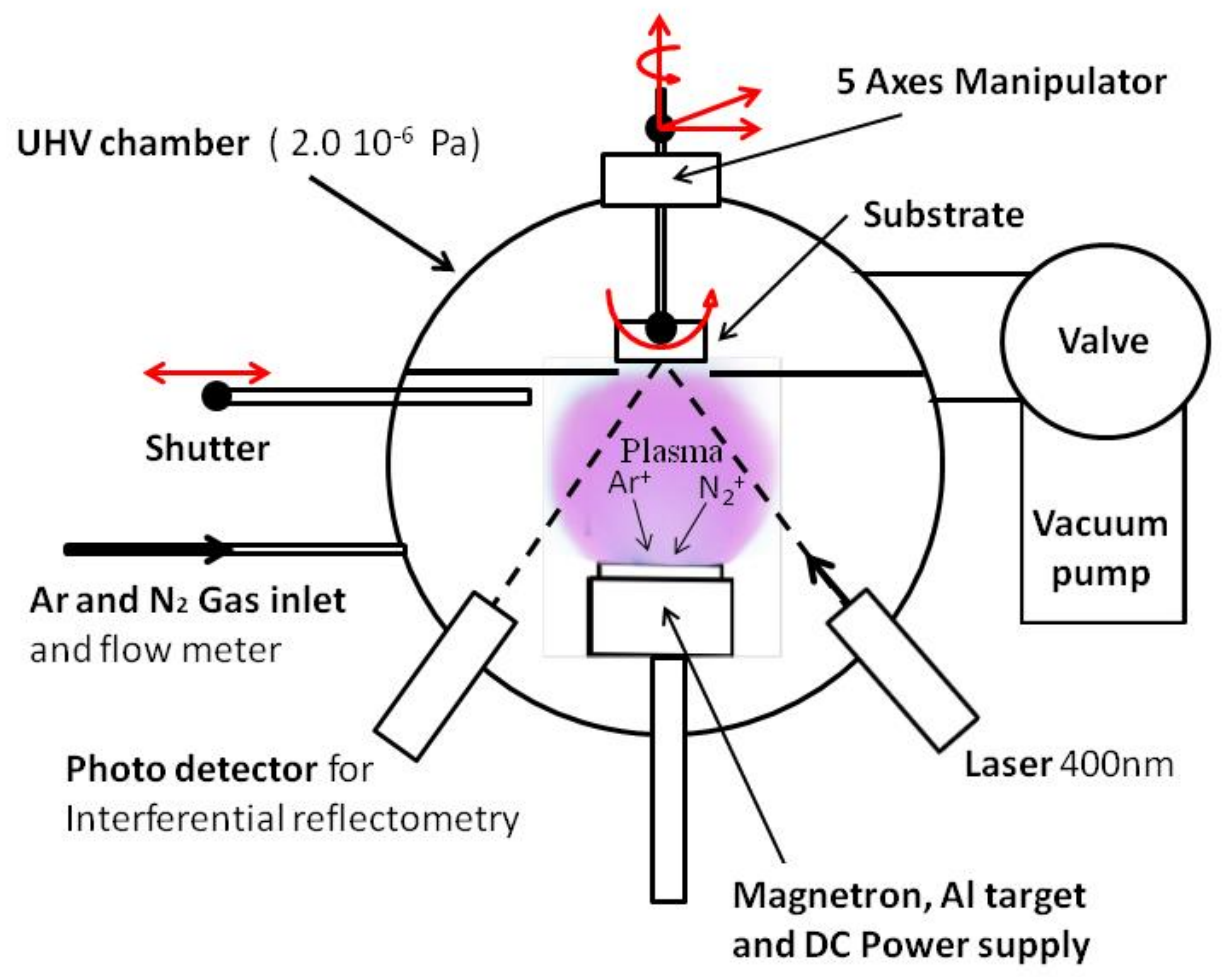


Figure (2)

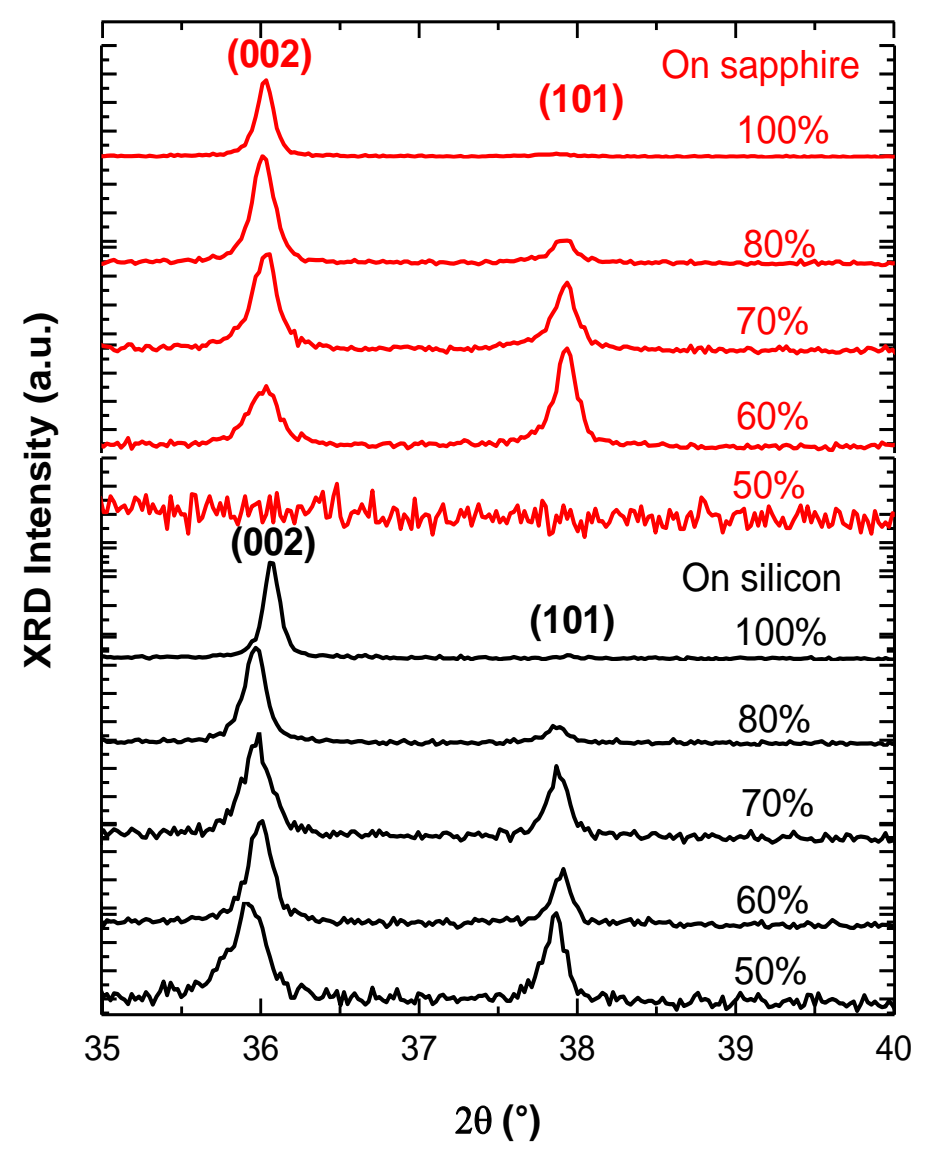


Figure (3)
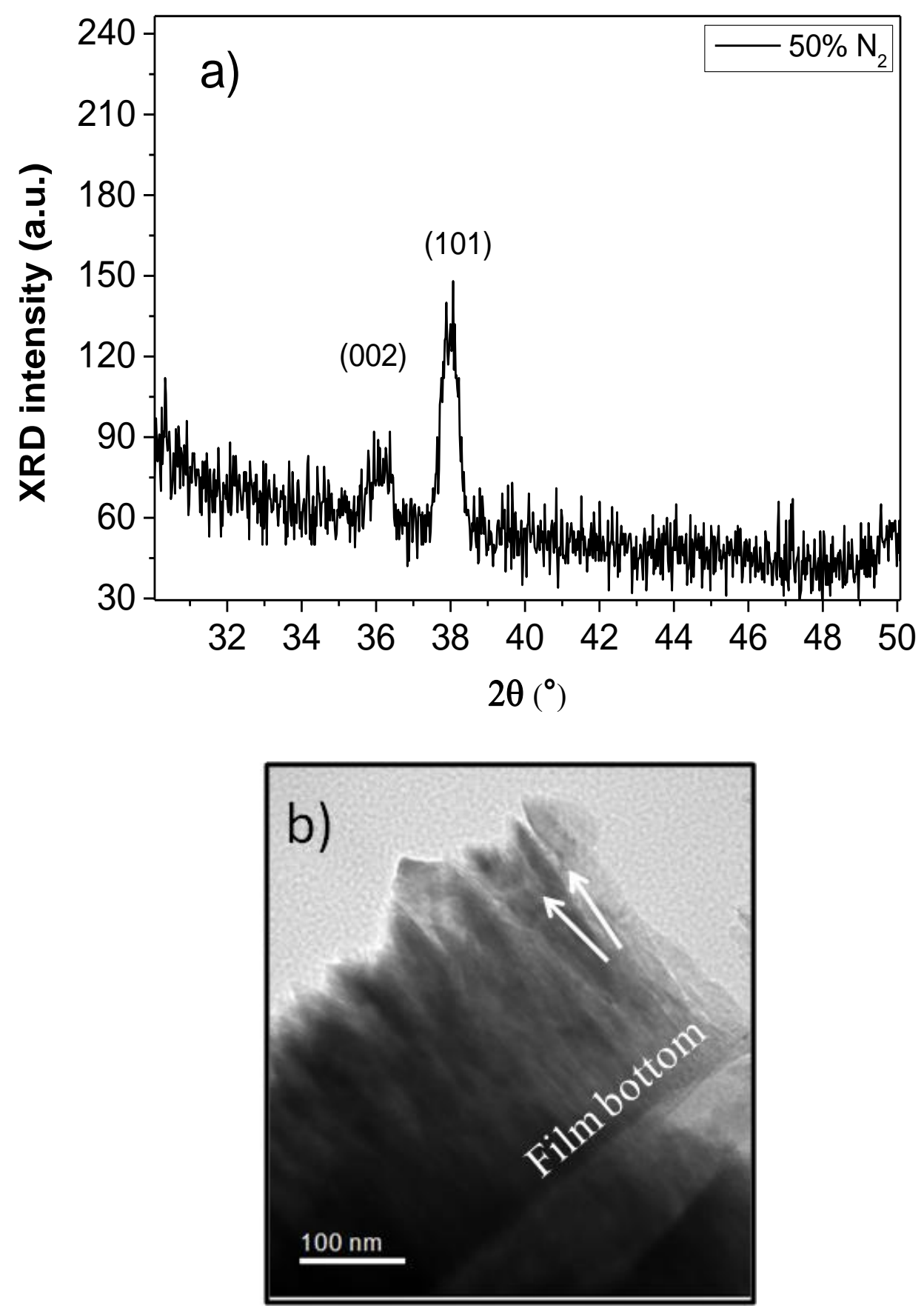
Figure (4)

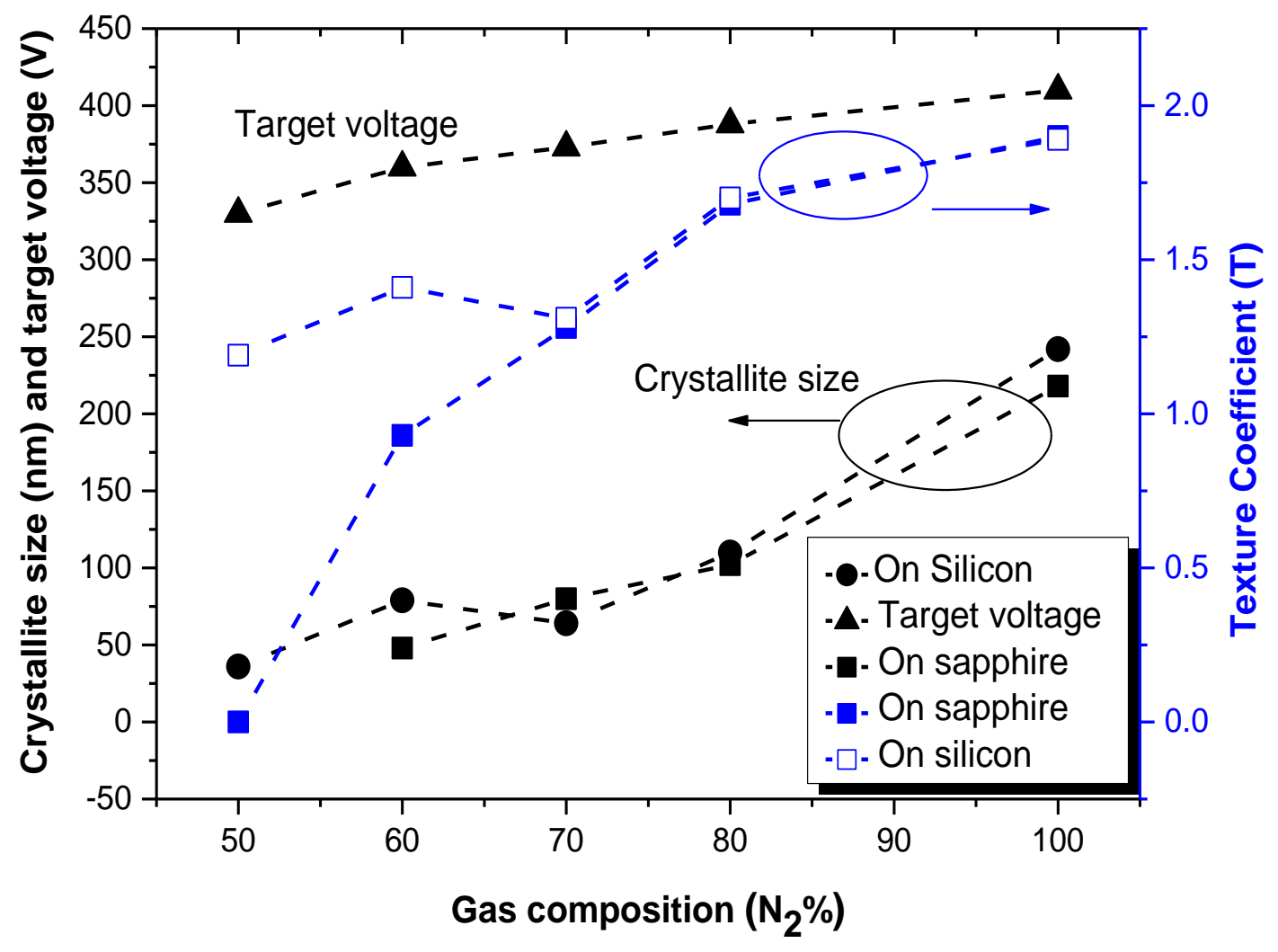


Figure (5)

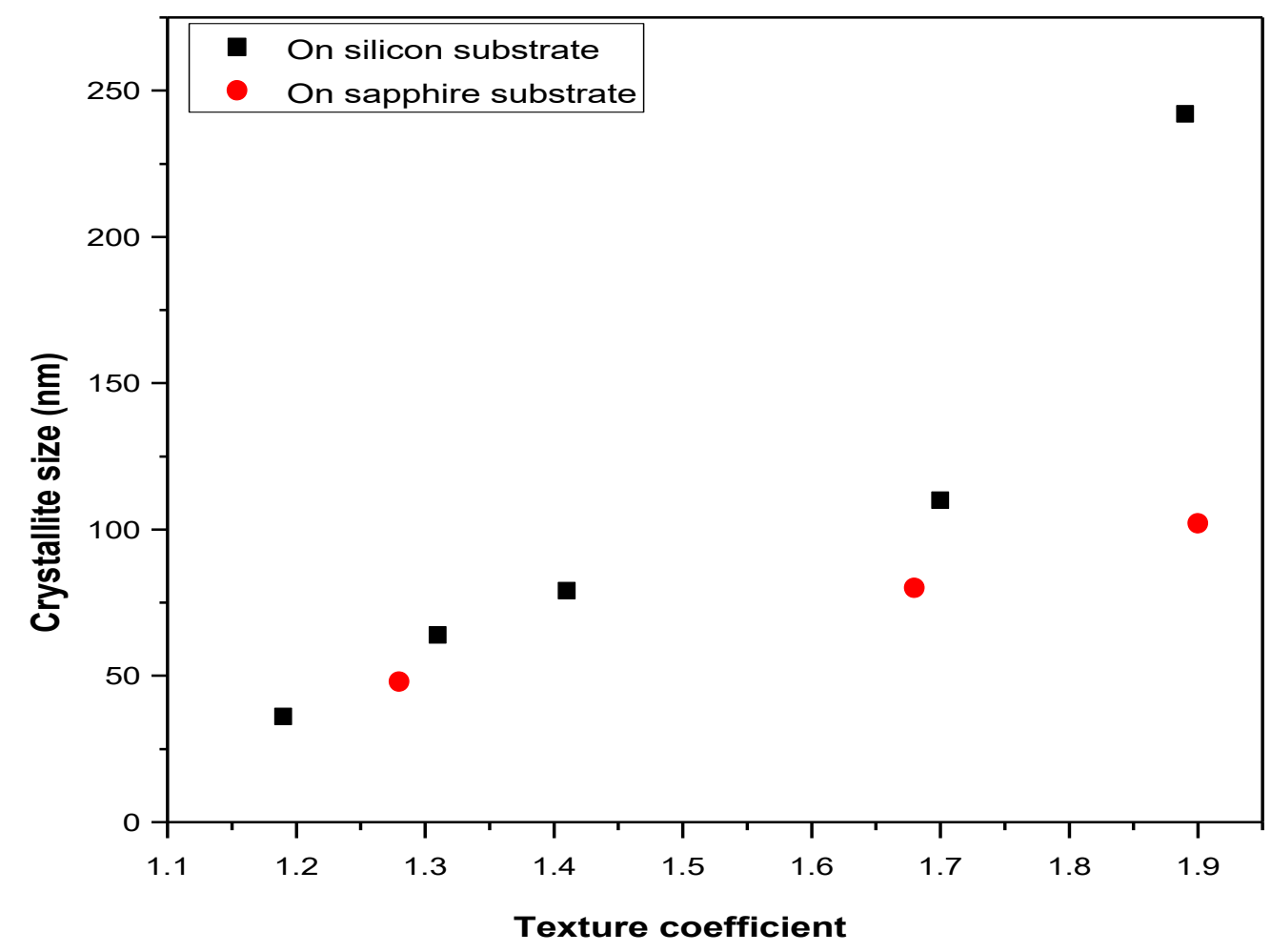


Figure (6)

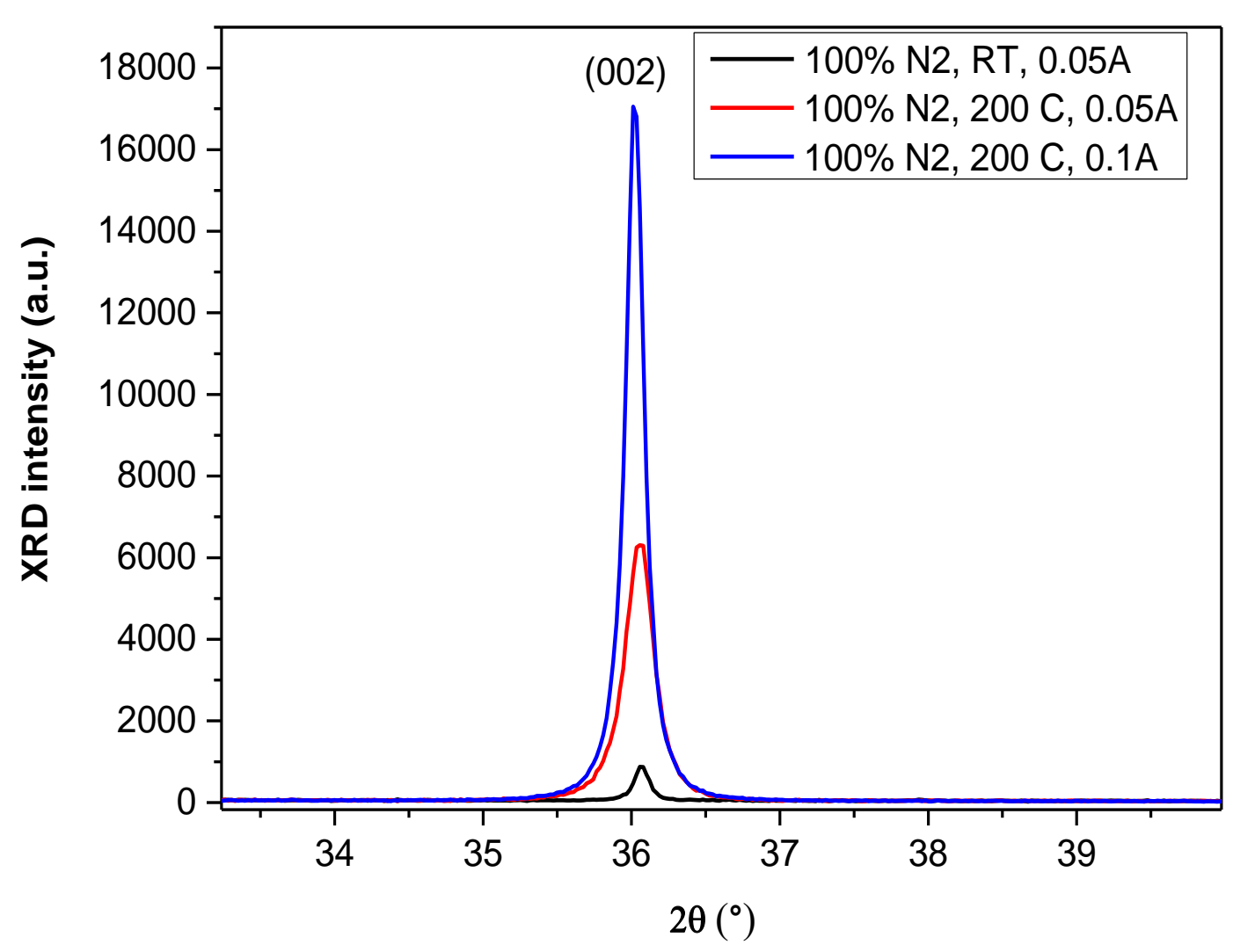


Figure (7)

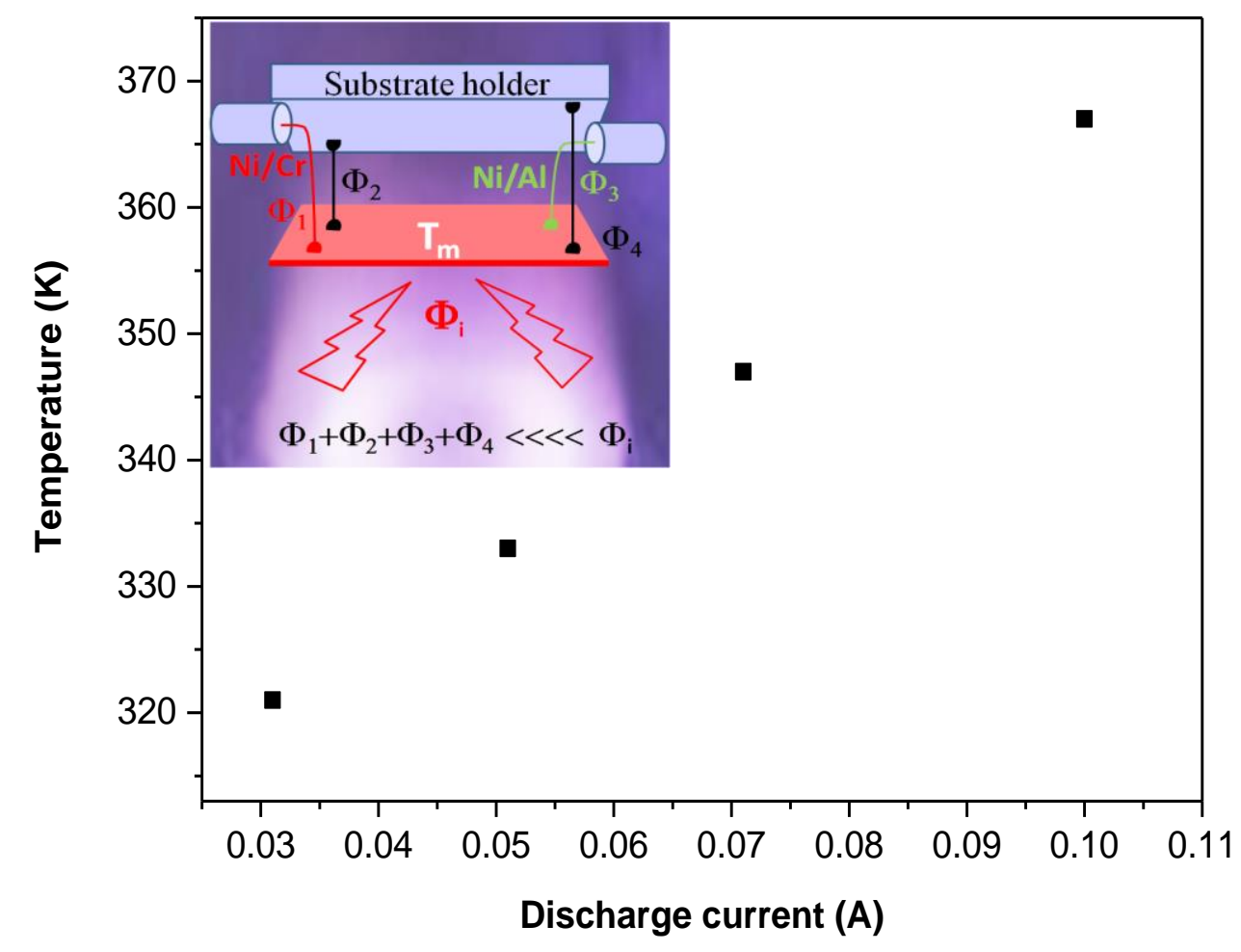


Figure (8)
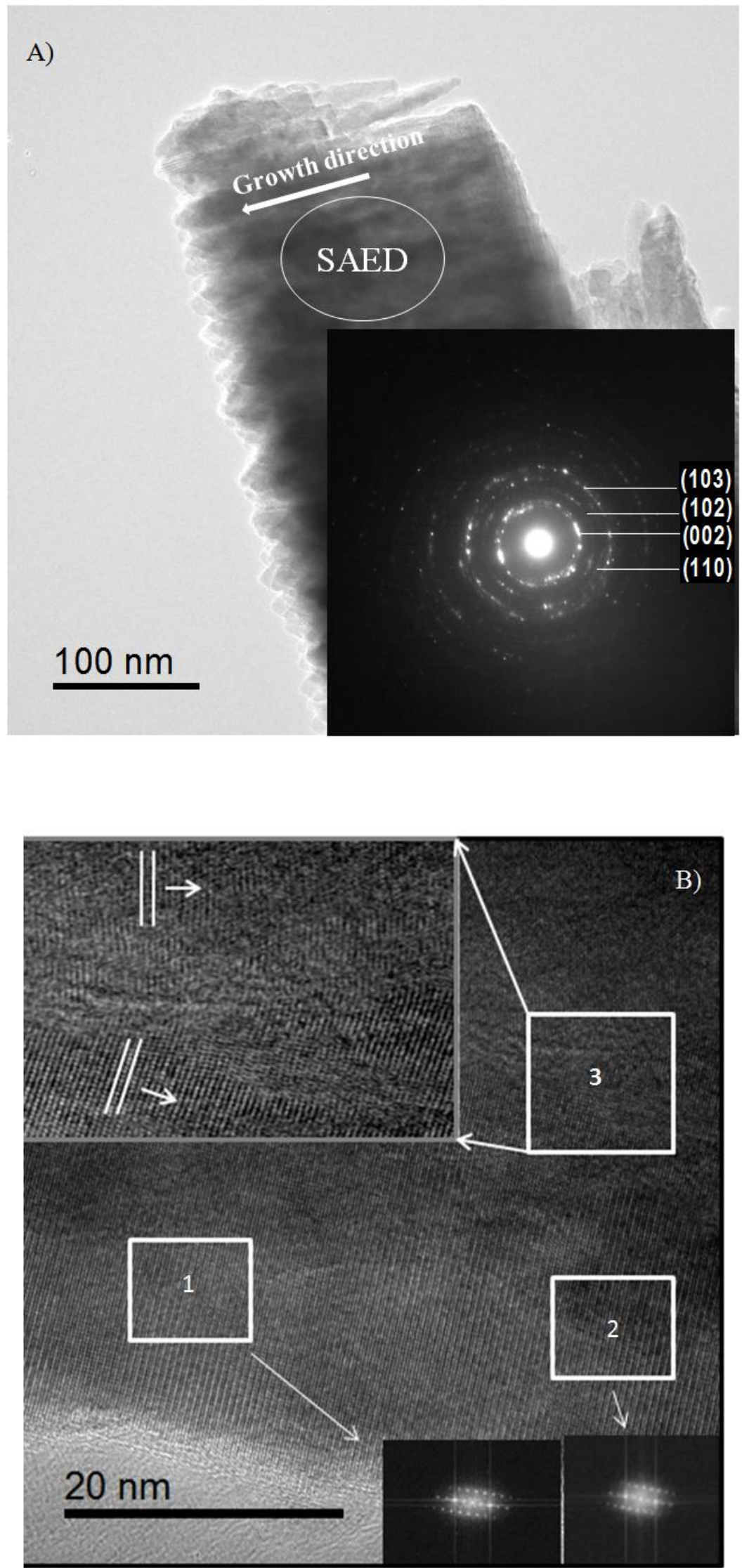

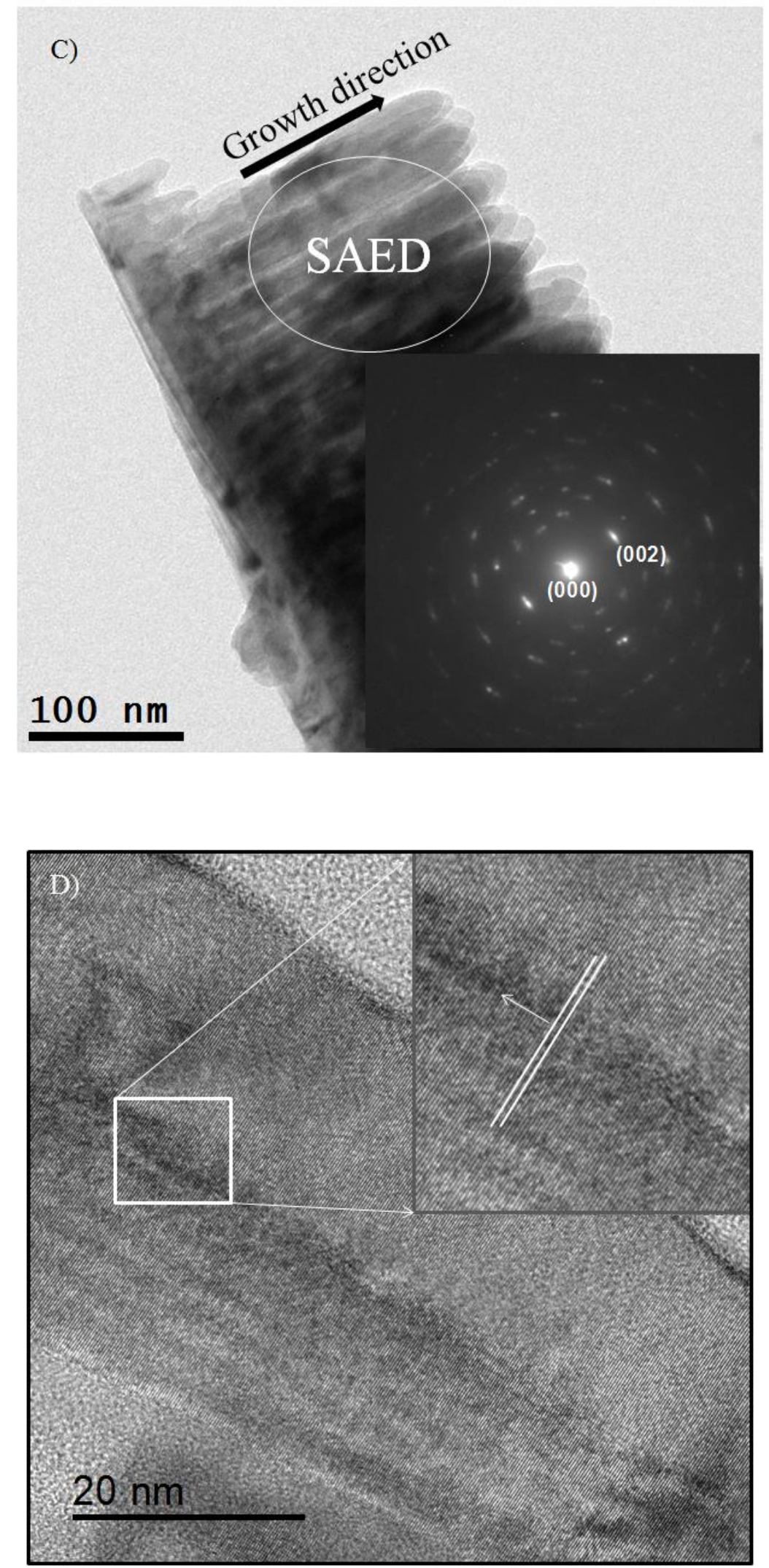
Figure (9)

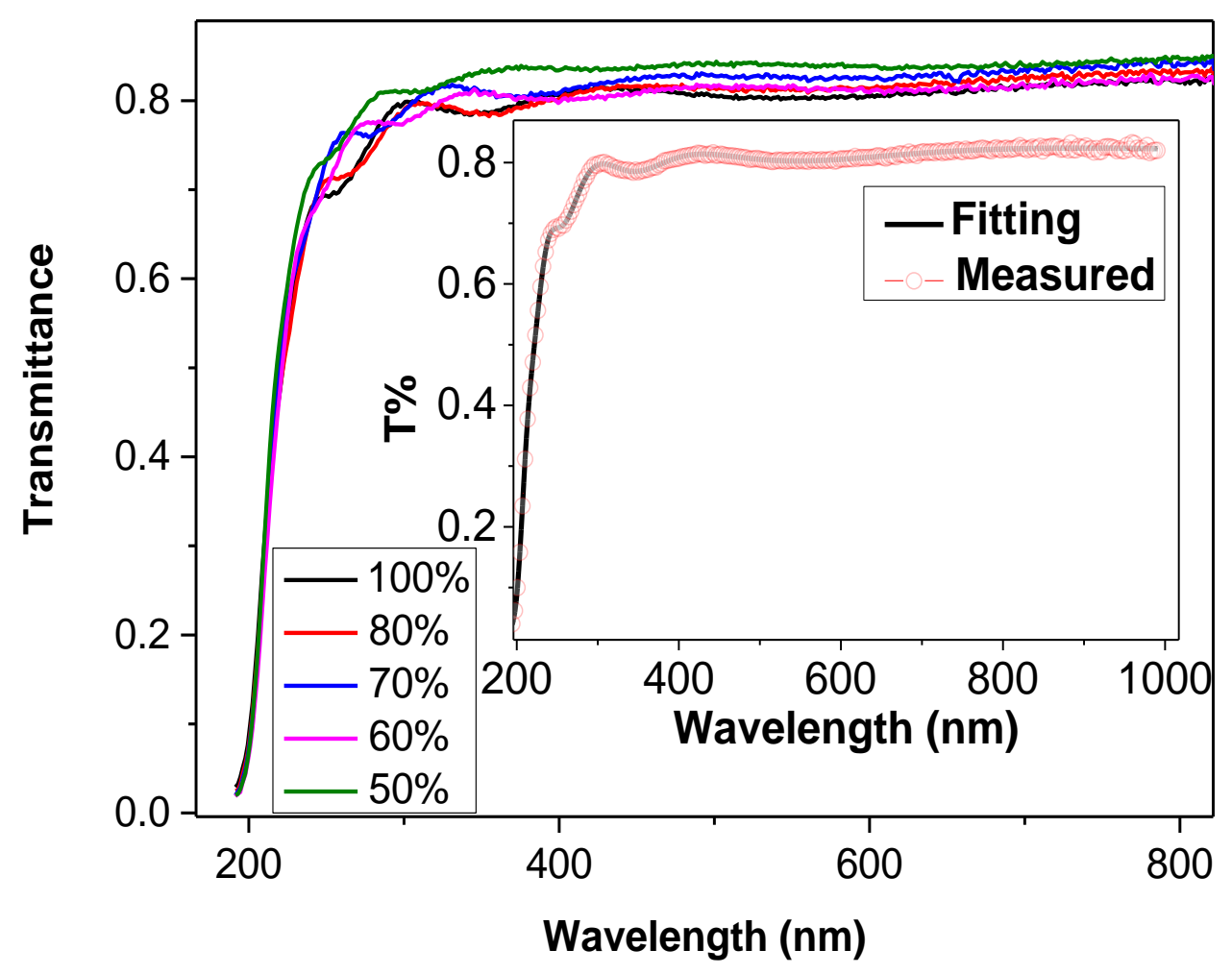


Figure (10)
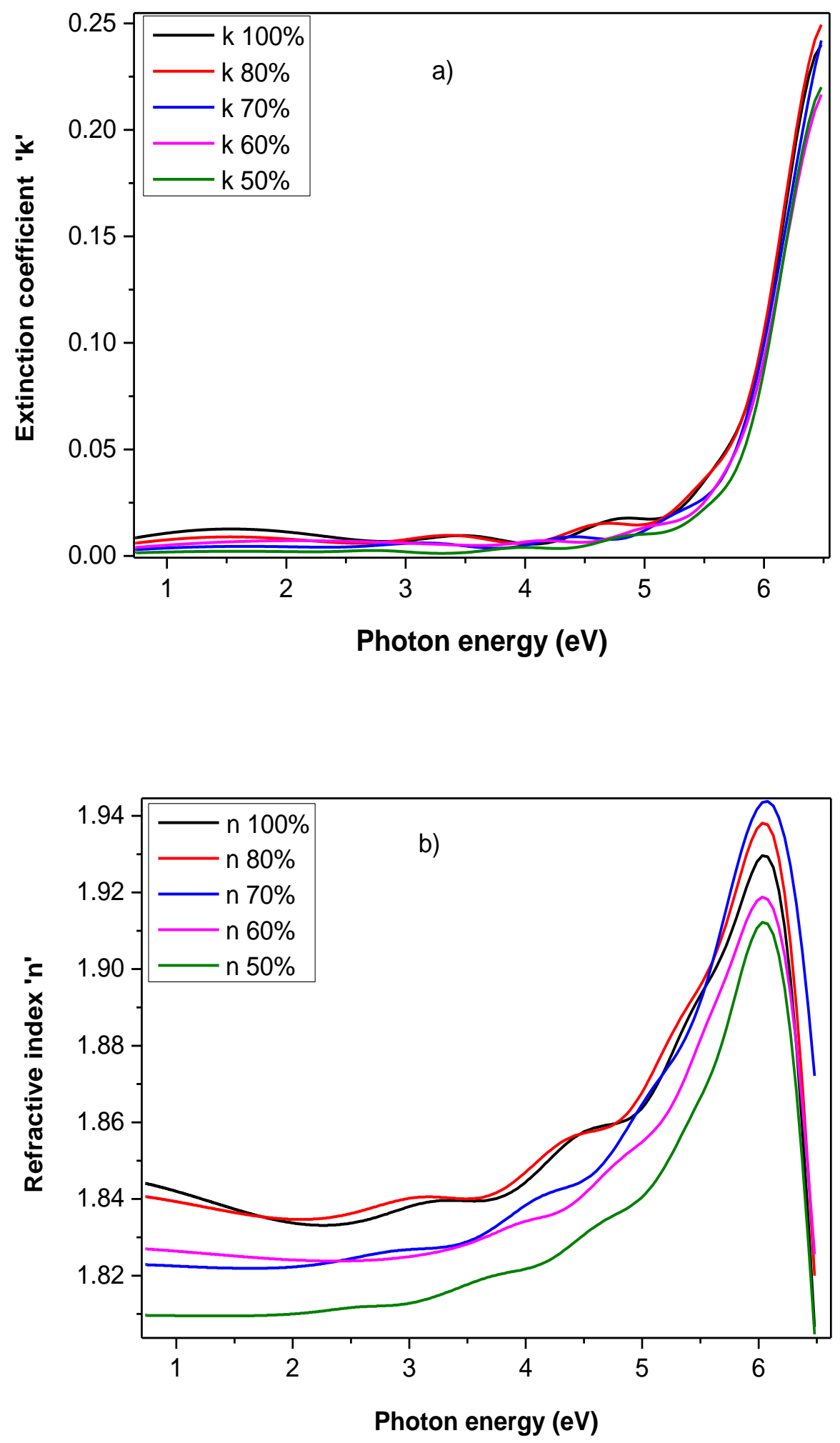
Figure (11)

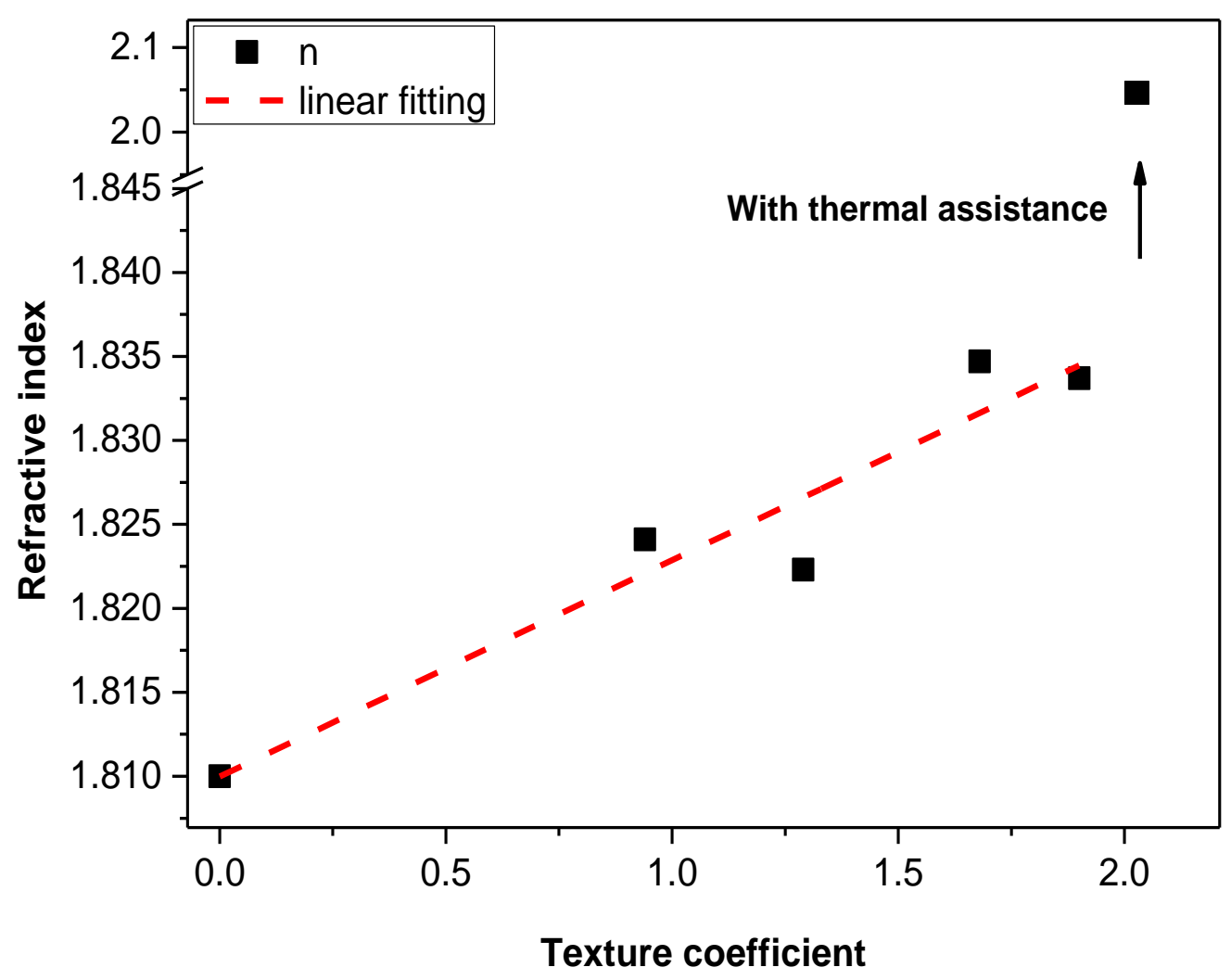


Figure (12)

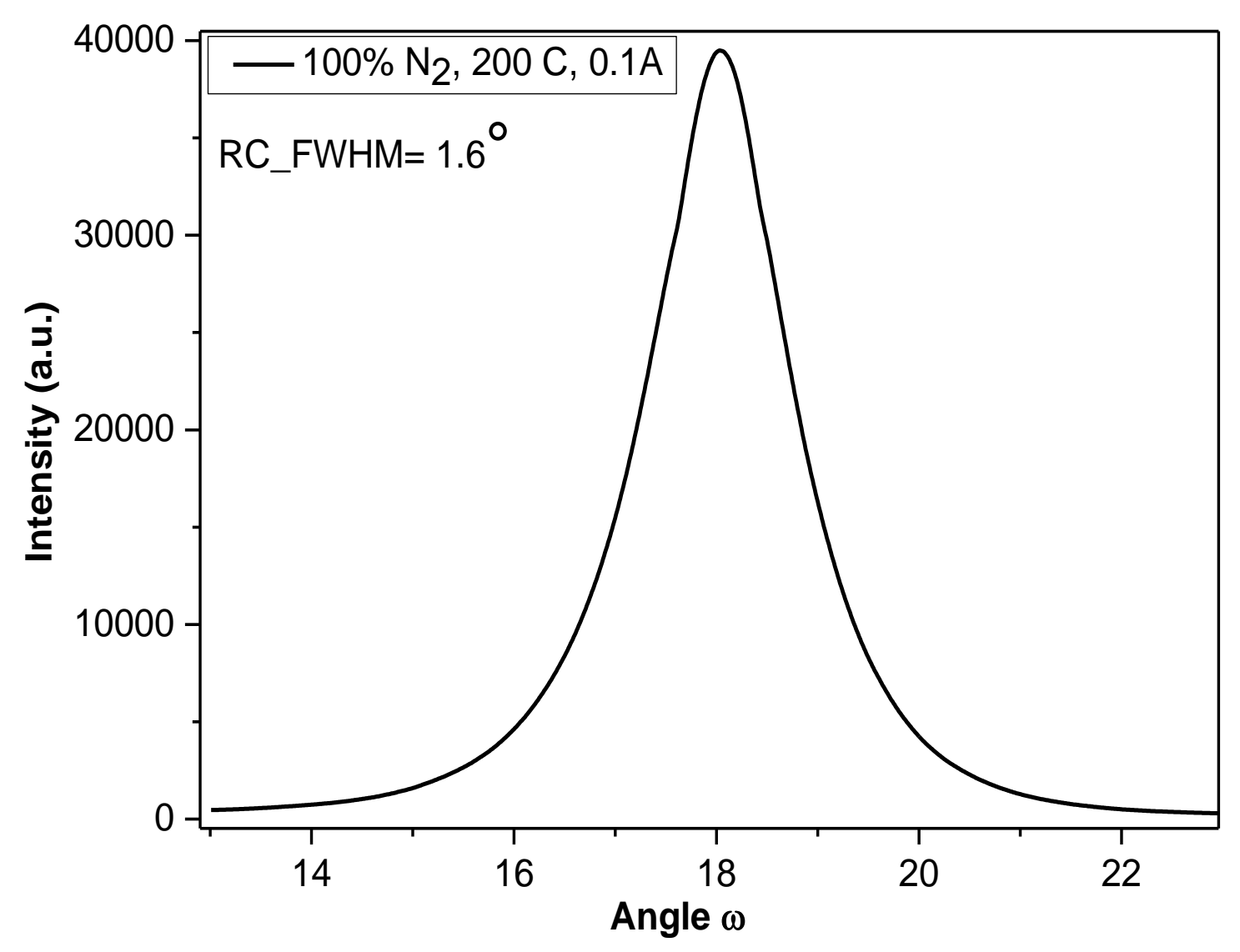

